\title{
Clinical Significance of a Hydroxyproline-containing Protein in Human Plasma*
}

\author{
E. Carwile LeRoy and Albert Sjoerdsma $\dagger$ \\ (From the Experimental Therapeutics Branch, National Heart Institute, \\ Bethesda, Md.)
}

Recently, we have identified a hydroxyprolinecontaining protein $(s)$ in human plasma (1) and developed a specific method for its assay (2). The behavior of this protein (hyproprotein) as shown in precipitation and gel filtration experiments indicates that it is a large molecule; its resistance to digestion by proteolytic enzymes suggests further that it may be a form of collagen (2). As part of a program of study to determine the significance and possible origin of this circulating protein, a survey was made of plasma hyproprotein levels in a large number of normal subjects and in patients with a variety of clinical disorders. Also, comparisons were made with the levels of excretion in the urine of hydroxyprolinecontaining peptides.

\section{Methods}

Subjects. These were 101 normal individuals and 146 patients with various diseases. The normal subjects ranged in age from newborn to 93 years. The newborns were from normal deliveries at the National Naval Medical Center, Bethesda, Md. Normal children and adolescents were either outpatients seen for routine checkup at the Navy Pediatric Clinic or volunteers from the Bethesda community. Normal adults in the 20 - to 70-year age range were either employees or hospitalized volunteers at the National Institutes of Health; the 70- to 93-year age range was comprised of residents of a nursing home in the Bethesda area. The patients studied ranged in age from 20 to 67 years and were seen at either the National Naval Medical Center or the National Institutes of Health.

Technique. Initially, blood samples from the antecubital veins of fasting subjects were drawn into .01 vol heparin (heparin sodium, 1,000 U.S.P. units per $\mathrm{ml}$ ). In later studies, the same relative amount of $40 \%$ (wt/ vol) sodium citrate was used as discussed under Results. The blood was centrifuged at $4^{\circ} \mathrm{C}$ for 30 minutes at $1,000 \times g$, and the plasma was separated. Routinely the

* Submitted for publication December 18, 1964; accepted February 15, 1965.

$\dagger$ Address requests for reprints to Dr. Albert Sjoerdsma, National Heart Institute, Bethesda, Md. 20014. plasma proteins were precipitated immediately; occasionally the plasma was stored at $-20^{\circ} \mathrm{C}$ for 1 to 3 days before assay.

Procedure. The procedure used for the assay of plasma hyproprotein (2) consists of precipitation of plasma proteins by cold ethanol, complete hydrolysis of the proteins by autoclaving overnight in alkali, separation of hydroxyproline from interfering materials by cation-exchange chromatography, and measurement of hydroxyproline by procedure II of Prockop and Udenfriend (3). The latter method was also used to measure urinary hydroxyproline. Urine for this determination was collected in acid while subjects were receiving a hydroxyproline-free diet that contained no meat, fish, gelatin, ice cream, or soft candies; ample protein was supplied by milk, eggs, and cheese.

\section{Results}

I. Conditions of plasma preparation. Heparin was used as the anticoagulant until it was realized that, after freezing and thawing, a material which contained hyproprotein was precipitated from heparinized plasma. In seven normal subjects and two subjects with elevated hyproprotein levels, the mean loss after 2 months at $-20^{\circ} \mathrm{C}$ was 31 and $47 \%$, respectively. Approximately one-half of this loss could be accounted for by the hydroxyproline of the heparin-insoluble precipitates. These precipitates contained about six times as much hydroxyproline per milligram protein as was present in ethanol precipitates of the fresh plasma.

Subsequently, sodium citrate was used as anticoagulant. Hyproprotein in citrated plasma was found to be unchanged in ten normal samples and in ten samples with elevated levels after storage at $-20^{\circ} \mathrm{C}$ for 3 months. The mechanism underlying the relative stability of the hyproprotein in citrate as compared with heparin was not investigated.

The possibility that the hyproprotein in plasma might arise by breakdown of cellular elements of the blood was studied. When whole blood was subjected to sonic vibrations with complete dis- 
ruption of the cellular elements, plasma prepared therefrom had the same hyproprotein level as plasma prepared in the usual manner from the same blood. Plasma prepared from fresh blood collected in siliconized glassware by centrifugation at $35,000 \times g$ for 1 hour at $0^{\circ} \mathrm{C}$ had the same hyproprotein level as plasma prepared by the usual $1,000 \times g$ centrifugation procedure. Also, platelet suspensions separated from red and white cells by centrifugation, washed 3 to 5 times in saline, and then hydrolyzed had no demonstrable hydroxyproline.

The hyproprotein level of serum was consistently 10 to $15 \%$ less than that in plasma prepared simultaneously from the same individual. This led to the routine measurement of hyproprotein in plasma. The consistent decrease in serum represented approximately the same amount of hyproprotein as was found in the precipitates of frozen and thawed heparinized plasma discussed above.

II. Normal variations in plasma hyproprotein levels. Results of the survey in normal individuals are presented according to age groups in Table I. The hyproprotein levels at various ages were similar except in the infant ( 2 weeks to 2 years) and the adolescent (10 to 19 years) groups, in which higher values were encountered. In infants there was no overlapping of values with any other age group, whereas the differences between adolescents and other ages were apparent only after statistical comparison. Four age groups contained at least six individuals of each sex (Table I), and the results in these subjects were analyzed separately for possible variations with sex. No obvious dif- ferences were noted although in age group 20 to 29 the mean value for females (7.0) was somewhat lower than the mean value for males (8.2). This difference was not significant $(p>0.05)$ when analyzed statistically.

Diurnal variation and the effect of diet on plasma hyproprotein were studied in two normal young adult volunteers. As illustrated in Figure 1 , only minor variations of plasma hyproprotein levels were observed during 7 days on a regular hospital diet followed by 7 days on a hydroxyproline-free diet. Also, as shown in Figure 2, no consistent variations were apparent in eight plasma samples collected at 3-hour intervals from each of two young adult subjects.

III. Plasma hyproprotein levels in certain disease states. A summary of the results obtained in disease states is given in Table II. It was not possible to make an exhaustive study of diseases in which one might suspect an alteration of connective tissue metabolism; also, several of the samples were obtained under less than ideal conditions, e.g., after long-standing disease or during therapy with drugs.

Elevated levels of plasma hyproprotein were found in a variety, of clinical states. No instance of a subnormal level was found. The most striking elevations were found in the group of neoplastic diseases, specifically in six patients with active, untreated Hodgkin's disease (Table II). Also four patients with sarcomas that histologically were producing bone or cartilage had uniformly elevated levels as did a single patient with reticulum cell sarcoma. Elevations were seen in

TABLE I

Variations with age of plasma hyproprotein in normal subjects

\begin{tabular}{|c|c|c|c|c|}
\hline \multirow[b]{2}{*}{ Age group } & \multirow[b]{2}{*}{$\begin{array}{l}\text { No. of subjects } \\
\text { (Sex distribution) }\end{array}$} & \multicolumn{3}{|c|}{ Plasma hyproprotein hydroxyproline } \\
\hline & & Mean $\pm \mathrm{SE}$ & Range & $\begin{array}{l}\text { Significance of } \\
\text { differences* } \\
\text { (p values) }\end{array}$ \\
\hline yrs & & $\mu g / m l$ & $\mu g / m l$ & \\
\hline Newborn & $7(3 \mathrm{M}, 4 \mathrm{~F})$ & $8.0 \pm 0.3$ & $6.9-9.1$ & NS \\
\hline 2 wks -2 yrs & $5(3 \mathrm{M}, 2 \mathrm{~F})$ & $12.6 \pm 0.8$ & $11.6-15.6$ & $<0.001$ \\
\hline 2-9 & $14(7 \mathrm{M}, 7 \mathrm{~F})$ & $7.7 \pm 0.4$ & $5.9-9.6$ & NS \\
\hline $10-19$ & $21(12 \mathrm{M}, 9 \mathrm{~F})$ & $8.8 \pm 0.3$ & $5.5-11.0$ & $<0.01$ \\
\hline $20-29$ & $25(18 \mathrm{M}, \quad 7 \mathrm{~F})$ & $7.9 \pm 0.6$ & $4.7-9.7$ & NS \\
\hline $30-49$ & $15(9 \mathrm{M}, 6 \mathrm{~F})$ & $8.0 \pm 0.3$ & $6.2-9.7$ & NS \\
\hline $50-69$ & $7(1 \mathrm{M}, 6 \mathrm{~F})$ & $8.1 \pm 0.3$ & $6.9-9.1$ & NS \\
\hline $70-93$ & $7(2 \mathrm{M}, 5 \mathrm{~F})$ & $8.2 \pm 0.3$ & $7.4-9.4$ & NS \\
\hline Total† & $75(40 \mathrm{M}, 35 \mathrm{~F})$ & $7.9 \pm 0.1$ & $4.7-9.7$ & NS \\
\hline
\end{tabular}

* Each group was compared with the total group using the $t$ test.

$\dagger$ Does not include age groups 2 weeks to 2 years and 10 to 19 years. 
TABLE II

Plasma hyproprotein levels in various diseases

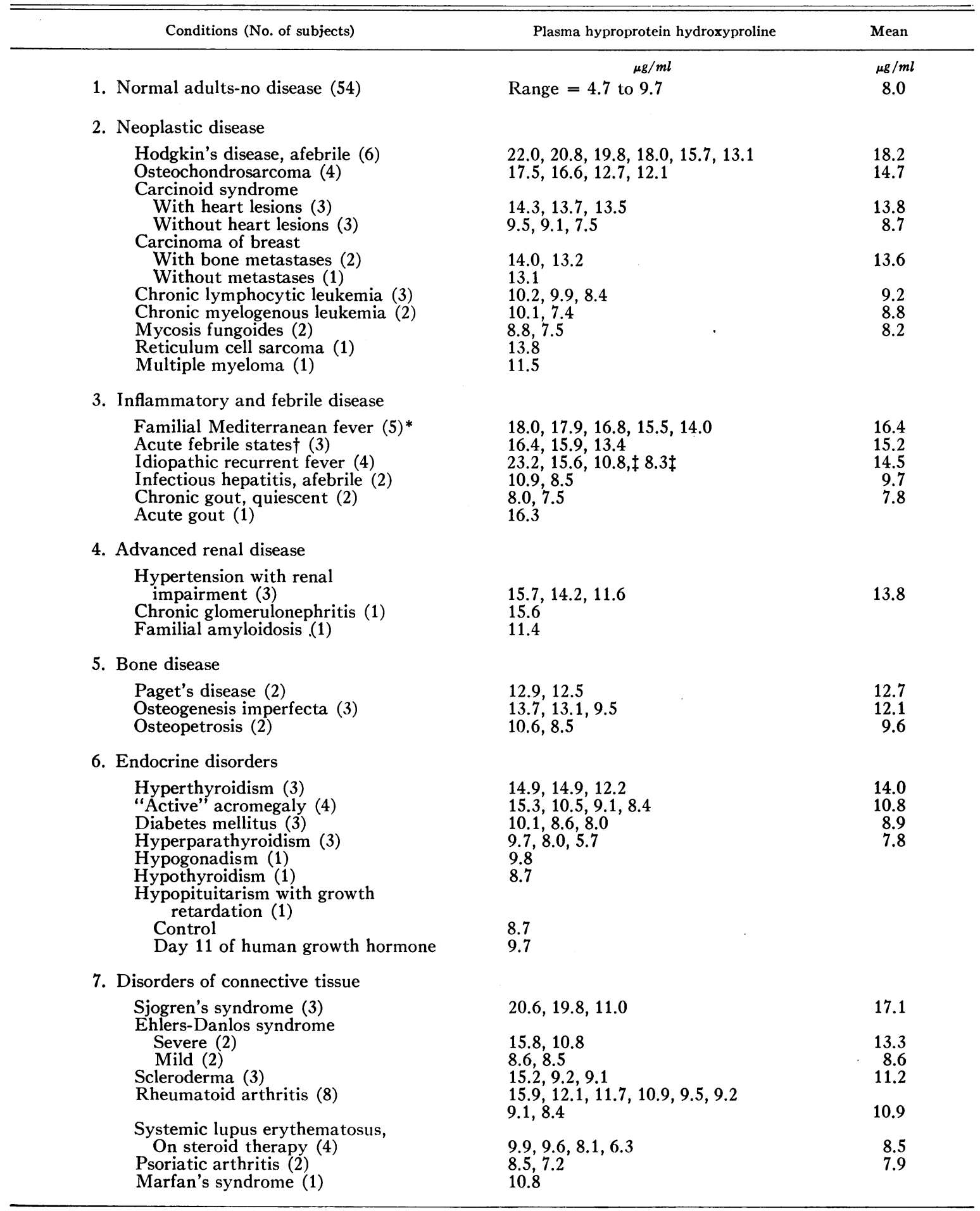

* In each case blood was obtained within 24 hours of the onset of a febrile attack.

$\dagger$ Acute thrombophlebitis with pulmonary embolus, systemic viral infection, and infectious mononucleosis.

$¥$ Blood was collected 24 and 48 hours, respectively, after an attack in these two cases. 
TABLE II-(Continued)

\begin{tabular}{|c|c|c|}
\hline Conditions (No. of subjects) & Plasma hyproprotein hydroxyproline & Mean \\
\hline \multicolumn{3}{|l|}{ 8. Hematopoietic disorders } \\
\hline Autoimmune hemolytic anemia (2) & $8.3,8.1$ & 8.2 \\
\hline \multicolumn{3}{|l|}{ 9. Cardiovascular disease } \\
\hline $\begin{array}{l}\text { Cardiomyopathy (2) } \\
\text { Rheumatic heart disease } \\
\text { Inactive (2) } \\
\text { Coronary artery disease (4) } \\
\text { Essential hypertension (12) }\end{array}$ & $\begin{array}{l}11.2,9.2 \\
11.4,6.2 \\
9.5,9.1,8.9,7.8 \\
10.3,9.9,9.1,8.8,8.1,8.0,7.6 \\
7.5,7.1,6.9,6.3,6.0\end{array}$ & $\begin{array}{r}10.2 \\
8.8 \\
8.8 \\
8.6\end{array}$ \\
\hline $\begin{array}{l}\text { 10. Miscellaneous } \\
\text { Mitral valve replacement (2) } \\
\text { Preoperative } \\
\text { Postoperative day } 11 \\
\text { Pregnancy and puerperium (7) } \\
\text { Postpartum, 10 days (1) } \\
\text { Miscellaneous elevated values } \$(2) \\
\text { Miscellaneous normal values\| (14) }\end{array}$ & $\begin{array}{l}11.4,6.2 \\
14.8,11.8 \\
10.3,9.5,9.1,7.4,7.3,6.5,6.3 \\
13.2 \\
11.4,10.5 \\
9.5,8.7,8.5,9.2 .8 .1,7.5,8.7,7.7,7.2 \\
6.7,7.3,9.2,8.4,7.7\end{array}$ & $\begin{array}{r}8.8 \\
13.3 \\
8.1\end{array}$ \\
\hline
\end{tabular}

\$ Pheochromocytoma and xanthinuria (1 each).

Synovioma, nephrotic syndrome, pseudoxanthoma elasticum, Hurler's syndrome, undiagnosed proliferative disease of tendon sheaths simulating gout (acute), cystinuria, myasthenia gravis, muscular dystrophy (2), amyotrophic lateral sclerosis, familial amyloidosis, idiopathic myopathy, recurrent thrombophlebitis, and Mikulicz's syndrome (one each in order given except as noted).

three patients with carcinoma of the breast; two of these had obvious metastases (including bone), and one had no clinical signs of metastatic disease. In six patients with carcinoid tumors and the carcinoid syndrome, elevations were observed only in the three patients in which the carcinoid heart lesion (4) was also present.

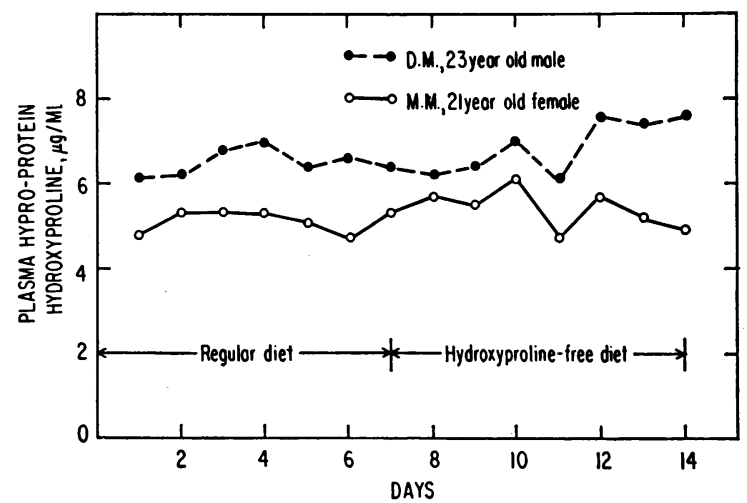

Fig. 1. DiURnal and dietary variations in PLASMa HYPROPROTEIN. Daily fasting blood samples for plasma hyproprotein determinations were obtained from two young adult volunteers ( $\bigcirc$ M.M., 21-year-old female; - D.M., 23-year-old male) on a constant diet of their choice for 1 week and a hydroxyproline-free diet for 1 week.
Elevations in plasma hyproprotein were also observed in febrile disorders of a diverse etiology and renal disease with azotemia and early uremia. Evidence for the presence or absence of fever or renal impairment was sought in the other disorders studied. With the exception of the patients included under Inflammatory and Febrile Disease (Table II, no. 3 ), no subjects had evidence of fever. Specifically, the six patients with

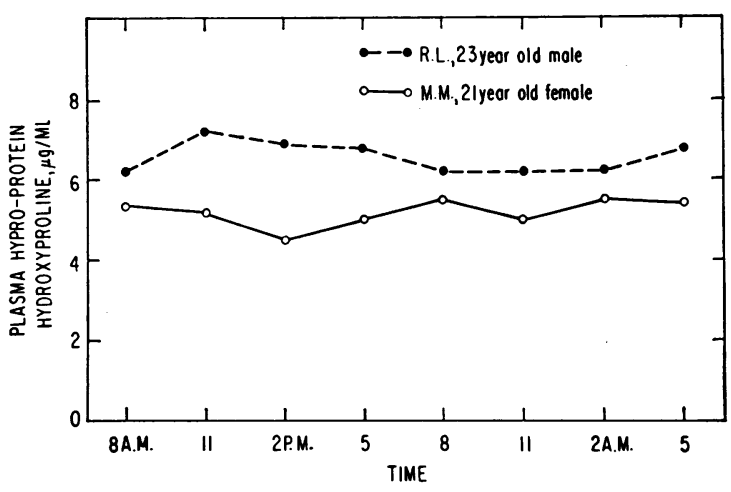

Fig. 2. Circadian variation in Plasma hyproproTEIN. Blood samples were obtained at 3-hour intervals during a 24-hour period from two young adult volunteers on a diet of their choice ( $O$ M.M., 21-year-old female; - R.L., 23-year-old male). 
Hodgkin's disease had recorded rectal temperatures of less than $37.5^{\circ} \mathrm{C}$ on each of the 5 days before the determination of plasma hyproprotein. Also, with the exception of those patients included under Advanced Renal Disease, there was no evidence of renal functional impairment as indicated by urinalysis, and either blood urea nitrogen or plasma creatinine level. Patients with several other specific diseases also exhibited elevated levels; the most conclusive data were obtained in hyperthyroidism, Paget's disease, Sjogren's syndrome, and Ehlers-Danlos syndrome with severe skin involvement (Table II).

IV. Relation between urine hydroxyproline and plasma hyproprotein. Two patients with Hodgkin's disease were placed on a hydroxyprolinefree diet and 24-hour urine collections and serial 10-ml blood samples were obtained for 6 days. Daily total urinary hydroxyproline and plasma
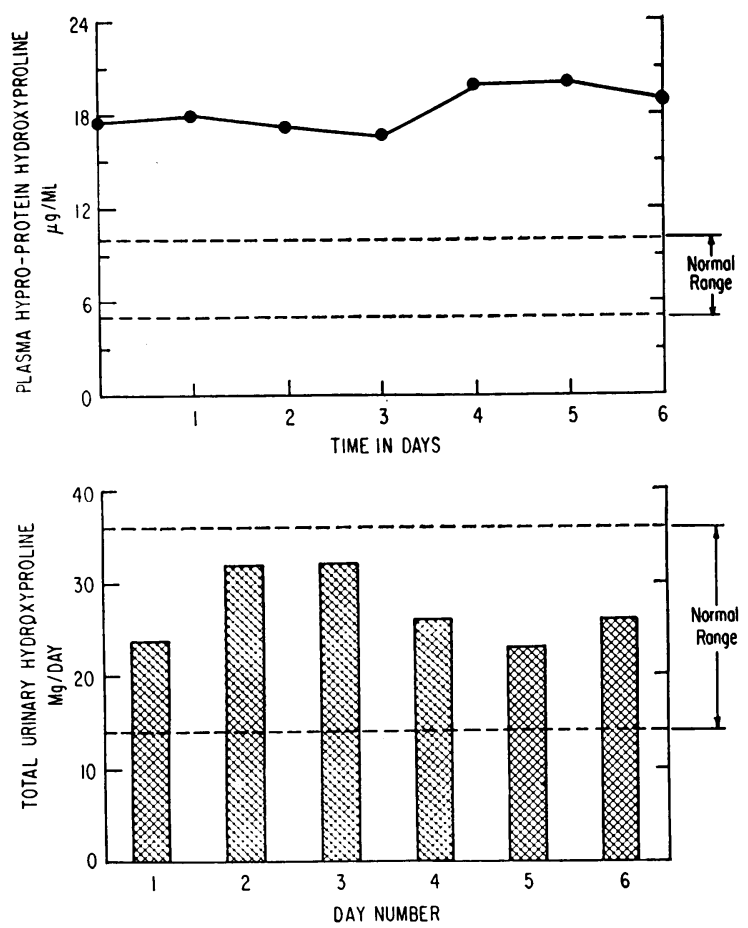

Fig. 3. COMPARISON OF PLASMA hYPROPROTEIN LEVELS WITH URINARY HYDROXYPROLINE PEPTIDE EXCRETION. TWO hospitalized adult males with Hodgkin's disease received a hydroxyproline-free diet beginning on the day before the collection of six consecutive 24-hour urine specimens. Daily fasting blood samples were obtained for plasma hyproprotein levels. The data presented are the averages of determinations in the two patients. hyproprotein levels are shown in Figure 3. These data demonstrate that a normal level of excretion of hydroxyproline peptides in urine may occur in the presence of distinctly elevated levels of plasma hyproprotein.

\section{Discussion}

Previous studies of collagen metabolism in the intact subject have been based primarily on the measurement of hydroxyproline in dialyzable peptides in the urine (5) and in protein-free filtrates of plasma (6). Elevated urine hydroxyproline levels, up to 5 to 10 times the levels of normal adults, have been observed in normal individuals during phases of rapid growth (e.g., adolescence) and in several disease states, including acromegaly, hyperthyroidism, hyperparathyroidism, Paget's disease of bone, Marfan's syndrome, "active" scleroderma, and Klinefelter's syndrome $(5,7)$. Hydroxyproline peptides are presumed to reflect collagen degradation $(8,9)$. Thus, comparison of the present data with the findings of studies on peptide-bound hydroxyproline in urine may afford some basis for determining the place of hyproprotein in the over-all scheme of collagen metabolism.

In contrast to the situation with urinary peptides, the levels of plasma hyproprotein are remarkably constant through a wide age range in normal individuals. Although distinctly higher levels of hyproprotein were observed in subjects aged 2 weeks to 2 years, the values obtained in adolescents were in the same general range as noted in adults. A lack of correlation between plasma hyproprotein and urinary hydroxyproline was observed also in the two patients with Hodgkin's disease, in whom levels of the former were considerably elevated while urinary hydroxyproline excretion was normal. On the other hand, slight elevations of hyproprotein were noted in some subjects with conditions in which elevated urinary hydroxyproline has been observed; these included patients with Paget's disease, hyperthyroidism, acromegaly, and scleroderma.

It seems reasonable to conclude that, if levels of hyproprotein are a reflection of collagen pool, this pool is probably distinct from the pool from which hydroxyproline peptides are derived. It is essential of course to determine the rate of turnover 
of plasma hyproprotein and to compare this to the turnover rates of hydroxyproline in other pools. Preliminary studies in our laboratory in animals indicate that such a study is feasible. The most serious qualification to any interpretation of the present data as it pertains to collagen metabolism, however, is that hyproprotein has not yet been chemically identified as collagen. Studies are in progress toward a final identification.

Regardless of the nature of plasma hyproprotein, the abnormalities observed in disease states merit additional comment. Most of the elevations of plasma hyproprotein were associated with active or acute phases of disease, and it can be argued that these changes are similar to those observed with "acute phase reactants" such as fibrinogen, haptoglobin, and C-reactive protein. Since none of these substances was measured, this question is unanswered for the present. The highest and most consistent elevations have been observed in Hodgkin's disease, perhaps as a reflection of the collagenous element of this "fibroproliferative" disorder. In preliminary studies we have found that serial determinations of hyproprotein levels may be helpful in assessing the activity of Hodgkin's disease and responses to therapy. Similar reasoning and application may be possible for a number of the disorders outlined in Table II, including the sarcomatous neoplasms and the chronic inflammatory disorders.

If current assumptions concerning the significant relationship between hydroxyproline and collagen are correct, plasma hyproprotein represents an easily accessible and hitherto unstudied parameter of collagen metabolism. Because of its larger molecular size, this protein seems more closely related to the intact collagen fibril than is the case with previously studied metabolites of collagen. The variety of disorders in which alterations were observed suggests that involvement of collagen is more common than histopathologic studies have indicated and that under some circumstances plasma hyproprotein may be a more sensitive index of collagen metabolism than those previously studied.

\section{Summary}

Measurements of a hydroxyproline-containing, collagen-like protein (hyproprotein) in human plasma have been carried out in 101 normal persons ranging from newborn to 93 years of age and in 146 patients with a variety of diseases. In comparison with reported levels of hydroxyproline peptide excretion, plasma hyproprotein levels were found to be remarkably constant in normal subjects regardless of age, although levels in infants and adolescents are slightly higher than in children and adults. Elevated levels of plasma hyproprotein were seen in association with a number of disorders, the most striking being in Hodgkin's disease. The possible significance of this protein as an index of collagen metabolism is discussed.

\section{Acknowledgments}

The cooperation of many physicians was required in this study. Valuable technical assistance was rendered by Mr. Rodman L. Turner.

\section{References}

1. Keiser, H., E. C. LeRoy, S. Udenfriend, and A. Sjoerdsma. Collagen-like protein in human plasma. Science 1963, 142, 1678.

2. LeRoy, E. C., A. Kaplan, S. Udenfriend, and A. Sjoerdsma. A hydroxyproline-containing, collagen-like protein in plasma and a procedure for its assay. J. biol. Chem. 1964, 239, 3350.

3. Prockop, D. J., and S. Udenfriend. A specific method for the analysis of hydroxyproline in tissues and urine. Analyt. Biochem. 1960, 1, 228.

4. Roberts, W. C., and A. Sjoerdsma. The cardiac disease associated with the carcinoid syndrome (carcinoid heart disease). Amer. J. Med. 1964, 36, 5.

5. Smiley, J. D., and M. Ziff. Urinary hydroxyproline excretion and growth. Physiol. Rev. 1964, 44, 30.

6. Prockop, D. J., H. R. Keiser, and A. Sjoerdsma. Gastrointestinal absorption and renal excretion of hydroxyproline peptides. Lancet 1962, 2, 527.

7. Jasin, H. E., C. W. Fink, W. Wise, and M. Ziff. Relationship between urinary hydroxyproline and growth. J. clin. Invest. 1962, 41, 1928.

8. Prockop, D. J., and A. Sjoerdsma. Significance of urinary hydroxyproline in man. J. clin. Invest. 1961, 40, 843.

9. Prockop, D. J. Isotopic studies on collagen degradation and the urine excretion of hydroxyproline. J. clin. Invest. 1964, 43, 453. 